\title{
Editorial
}

\section{New ways to gain insight into new behaviours}

\author{
Journal of Direct, Data and Digital Marketing Practice (2013) 15, 103-104. doi:10.1057/dddmp.2013.59
}

How do we find out more about our customers and prospects? It is a critical question for digital and direct marketers and points to the importance of data in both. The better we know our audience, the more relevant our offers and messages become. Even the choice of where to engage with the market can be optimized by applying more and better data.

Getting to this nirvana is no easy task. For one thing, if we ask consumers directly, they do not always provide correct answers. Only a handful will actively lie about things such as demographics (their age, gender etc), although they may be tempted to exaggerate some aspects, such as income. But if you want to know what products or services they intend to buy, or what features and price points are the most attractive, consumers cannot always give good answers because they simply do not know themselves. Try it for yourself - write out a list of what you plan to buy in the coming month, then look back at it and see how accurate it was.

In real-world conditions, consumers face a welter of choices and are often making snap judgements between competing options. This is where the notion of System 1 and System 2 thinking, as proposed by Nobel Prize-winning economist Daniel Kahneman, comes into play. Given the right conditions, such as full information and endless time, consumers will behave rationally (System 2 thinking). As these conditions seldom exist, they have to make snap judgements (System 1).

Now, which of these responses do you think market research or surveying is likely to generate? And how different from live behaviour will those responses be? Our main whitepaper, 'Research in a world without questions', examines how to move consumer insight forwards to take this into account, laying out a framework and showing a live example of how effective it can be.

Behavioural economics has become extremely popular with marketers, not least because digital channels now make it easier to observe exactly what prospects and customers are doing. Translating that visibility into an actionable marketing strategy requires robust data and accurate modelling. The experience of Piano Media in using a new profiling solution (see Case History on pages 108-110) proves that there are now sustainable, effective ways to identify individuals, even at the anonymous prospect stage, and to segment them by psychographical profile. Since attitudes drive behaviour, this hands back some of the control to marketers that they feel has been lost to the influence of social media.

This concern that technology and channels are diluting consumer attention and propensity to be influenced by marketers may in itself be overstated. Research carried out by fast.MAP on behalf of the Institute of Direct and Digital Marketing (IDM) (see pages 160-165) shows that marketers are overestimating the adoption rate of mobile technology and missing the new influences on consumers, such as reviews. Working to close this gap will not only make marketing more relevant, it will also help to improve campaign performance.

Of course, there are still many things about the future that are not only hard to predict, they are also threatening to existing business models and marketing frameworks. Listening to the futurologists and transformational businesses at the DataIQ Future Summit (see review on pages 170-176), it was possible to be both excited and scared at the prospects. Listening to advocates of open data is likely to generate far more excitement than fear, however. Here is a brand new realm that is still largely uncharted and whose potential is unproven. It could be that, as members of the Open Data Institute (ODI) believe, everything will be changed for the better, as you can find out on pages 176-179. The value of their predictions is yet 


\section{桨. Editorial}

to be proven. However, by taking an early decision to engage directly with the ODI, the IDM is putting itself into the right place to see some of those benefits for itself and its members. That starts with the new Open Data for Marketers training programme, but other potential outcomes are unlimited. As is the future itself, indeed.

David Reed FIDM 